\title{
Study on the Building Mechanism of Straw Immobilized Microorganisms
}

\author{
Xiuxia Zhang", Qiongqiong Shang, Hongting Zheng and Zhesen Zhong \\ Department of Environment and Safety Engineering, China University of Petroleum, Shandong Qingdao 266580, PR. China \\ ${ }^{*}$ Corresponding author
}

\begin{abstract}
Using the single hydrocarbon degrading bacteria, two kinds of straw materials called MG and SY as the carrier, and then preparing two kinds of immobilized microbs by adsorption, examining their strain absorption rate and petroleum hydrocarbon degradation rate after 7 days. Characterizing the morphology of straw carrier material and immobilized microbs before and after the degradation of oil by SEM and BET. The results showed that : strain absorption rate of immobilized bacterial immobilized by $\mathrm{SY}$ and the petroleum hydrocarbon degradation rate after 7 days is higher than MG. Straw SY is a desired carrier material, because of its high surface roughness, specific surface area, mechanical strength and stable structure is better.
\end{abstract}

Keywords- immobilized microorganisms; straw materials; building mechanism component

\section{INTRODUCTION}

Currently, about 800 million tons of oil around the world enter the environment and cause pollution. The technology of microbial immobilization has become a research hot spot in the area of oil pollution control, it also has a special technological advantage and a good prospect.

The physical and chemical properties of the carrier used in immobilized cell technology affects the biological activity of the fixed cells and the system's mass transfer performance directly[2, 3]. Straw carrier immobilized microorganisms is the immobilized microorganism which is prepared using agriculture straw as the carrier and the efficient petroleum hydrocarbon degrading bacteria as the main part. G.Y.XU[4] say that different stalk has different morphology. The immobilized microorganism using haulm as straw can enhance the biodegrading procedure of kerosene and shorten the time span of degrading[5]. The immobilized microorganism using cornstalk as straw bring out favourable effect in the fermentation producing procedure of acetonum, ethylalcohol and butanol[6]. It put up a good degradation properties of chlorophenasic acid in soil and the degradation rate is higher than the free strain[7]. Podorozhko' study shows that the pine sawdust being treated has a good properties if used as the carrier material for immobilized[8].

De Castro H. F.[9], ect. used haulm as carrier to immobilize the lipase, the polyethyleneglycol as stabilizer and the glutaraldehyde to active the haulm, then they studied the effect of polyethylene glycol molecular-weight and the carrier fixed amount of enzyme, result showed that the immobilized microorganism lipase put up higher hydrolytic and synthetic activity. Vega, F.A., ect.[10] used the sewer sludge and the barley straw building of immobilized microorganism, and then used the immobilized microorganism to absorb and degrade the heavy metal ion exist in the copper mine region and $\mathrm{Pb}^{2+}$, etc., they draw adsorption/desorption isotherm, evaluated the adsorption amount of immobilized sludge and the reversibility of adsorption.

This article is about the building mechanism of straw immobilized microorganisms by the determination of the amount of bacteria suction, stability of the immobilized microorganisms, oil absorption and other factors.

\section{MATERIALS AND METHODS}

Immobilization Carrier Material Microbial Absorption Measurement. Experiment were divided into three groups, that was immobilized bacteria, free bacteria and blank control(only carrier material), put them into conical flask for 24 hours, and then measured the bacteria absorption amount of the immobilized carrier, the methods were as follows.

(1)transferred the immobilized petroleum hydrocarbon degrading bacteria and blank control material to a centrifuge tube with $10 \mathrm{~mL}$ saline, centrifuged for $5 \mathrm{~min}$ under the condition of 1000rpm speed, then filtered the supernatant liquid into a $50 \mathrm{~mL}$ volumetric flask, repeated this step three times.

(2)Volumed the above $50 \mathrm{~mL}$ volumetric flask with saline, and then shake it well, measured its absorbance at $600 \mathrm{~nm}$ with $\mathrm{UV} / \mathrm{V}$ is spectrophotometer, each sample was measured three times, averaged the result. Converted absorbance values of experimental group and the control group into the efficiency of bacteria the carrier immobilized to represents bacteria absorption amount of the carrier material.

Measurement of Degradation Effect of Two Kinds of Straw Immobilized Microbial. Prepared immobilized microorganisms by adsorption, using the single efficient hydrocarbon degrading bacteria as bacteria source, two kinds of straw materials called MG and SY as the carrier. Added the two kinds immobilized microorganisms to the crude oil culture medium respectively for 7days. After petroleum ether dissolved and oscillation extraction, determined petroleum hydrocarbon concentration by UV spectrophotometry, and then calculated the petroleum hydrocarbon degradation rate.

$$
\eta_{d}=\left(C_{0}-C_{1}\right) / C_{0} \times 100 \%
$$


In the formula: $\eta_{\mathrm{d}}$-degradation rate, $\% ; \mathrm{C}_{1}$-residual oil content after treatment, $\mathrm{mg} / \mathrm{L} ; \mathrm{C}_{0}$-crude content in the system before treatment, $\mathrm{mg} / \mathrm{L}$

\section{A. Associated Performance Characterization of Immobilized Microorganisms}

Specific Surface Area, Pore Volume and Pore Size. After freeze and dehydration treatment, the two immobilized microorganisms were placed in liquid nitrogen environment, and then measured the parameters of immobilized microorganisms.

Morphological Structure Scanning Electron Microscope of Immobilized Microorganisms. Dehydrated, freezed and sprayed two kinds of carrier material, and then observed the surface and internal structure whether immobilized microorganisms before degradation or after by scanning electron microscopy.

Oil Absorption Measurement of Straw Immobilized Microorganisms.

$$
\eta_{a}=C / C_{0} \times 100 \%
$$

In the formula : $\eta_{\mathrm{a}}$-Adsorption rate, $\%$; $\mathrm{C}$-adsorbed petroleum hydrocarbon concentration, $\mathrm{mg} / \mathrm{L} ; \mathrm{C}_{0}$-initial petroleum hydrocarbon concentration, $\mathrm{mg} / \mathrm{L}$.

Operating conditions: Added $50 \mathrm{~mL}$ crude mineral medium and $2.0 \mathrm{~g}$ immobilized microorganisms material to $250 \mathrm{~mL}$ in $30^{\circ} \mathrm{C}$, then shaked the conical flask in the shaker under the condition 140rpm for 2 hours. In the case of 2000 times amplification, observed changes of two kinds of immobilized microorganisms before and after adsorbing oil by electron microscopy, including internal structure, distribution location of gap, oil absorption and so on of the immobilized microorganisms.

\section{RESULTS AND DisCUSSION}

Bacteria Absorption Amount Determination of the Carrier Material. The Immobilized rate was $43.11 \%$ and $54.69 \%$ by MG and SY carrier respectively. According to the comparison of bacteria amount on different carriers, it illustrated that SY can fix and enrich microbial easier than MG, the SY supplied a more suitable environment for microbial loading.

Degradation Rate Determination of Straw Immobilized Microbial. The result shows that, the efficient petroleum hydrocarbon degrading bacteria immobilized by SY and MG carrier respectively reached $55.6 \%$ and $36.6 \%$ after 7 days. SY showed a better degrading effect, combining the result of the amount, determined to choose SY as the best carrier.

Characterize the Morphology of Immobilized Microorganisms by SEM and BET

Measurement of Specific Surface Area, Pore Volume and Pore Size Distribution.

TABLE I. SPECIFIC SURFACE AREA AND PORE SIZE

\begin{tabular}{c|ccc}
\hline BET & Specific surface area $\left[\mathrm{m}^{2} \cdot \mathrm{g}^{-1}\right]$ & Pore volume $\left[\mathrm{cm}^{3} \cdot \mathrm{g}^{-1}\right]$ & Aperture $[\mathrm{nm}]$ \\
\hline SY & 2.0878 & 0.0043 & 6.7342 \\
MG & 2.8001 & 0.0051 & 12.0946 \\
\hline
\end{tabular}

As can be seen from Table 1, pore volume of SY and MG had little difference, since the value of specific surface area was not accurate after its crushing. MG had a large aperture ratio than SY.The pore size were both between $6 \mathrm{~nm}$ and $13 \mathrm{~nm}$, smaller than the diameter of general bacteria $(0.5-5 \mu \mathrm{m})$. Because
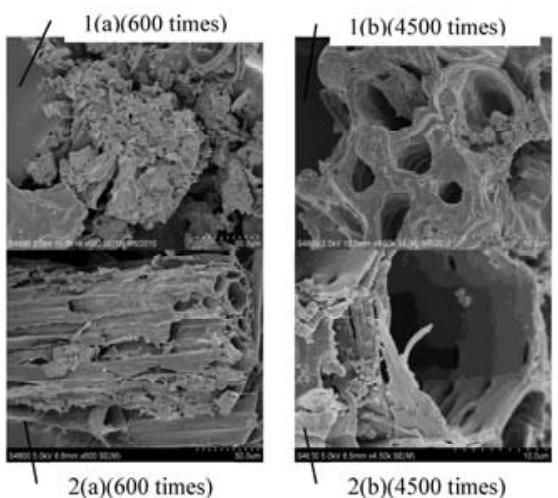

of this, the bacteria can not enter into the inner hole of the straw carrier, the enzymes and coenzyme bacteria secreted could. Then it adsorbed in the bore in contact with petroleum hydrocarbons and play a role in the degradation. sdf

Scanning Electron Microscopy.

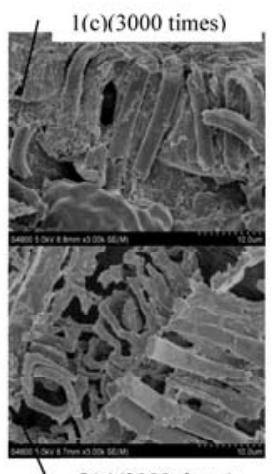

2(c)(3000 times)

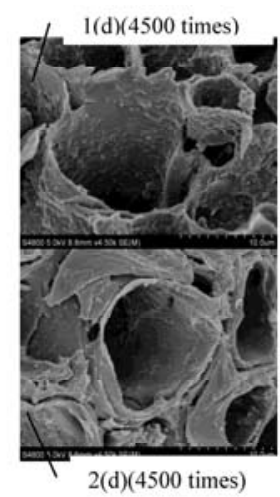

FIGURE I. (A) ORIGINAL VIEW OF SY. FIG. 1(B) INTERNAL HOLES OF SY. FIG. 1(C) SURFACE OF SY IMMOBILIZED BACTERIA. FIG 1(D) INTERNAL STRUCTURE OF SY IMMOBILIZED BACTERIA. FIG. 2(A) ORIGINAL VIEW OF MG. FIG. 2(B) INTERNAL HOLES OF MG. FIG. 2(C) SURFACE OF MG IMMOBILIZED BACTERIA. FIG. 2(D) INTERNAL STRUCTURE OF MG IMMOBILIZED BACTERIA 
From figure 1(a) and 2(a), we can see that the MG has a rules and smooth surface, while the SY had a rough. It can be seen from figure 1(b) and 2(b), that there were obvious pore structure on the two carriers, MG had larger aperture ratio than SY, which was the same with the BET analysis. Figure 1(c) and 2(c) shows that the straw adsorbed a lot of bacteria that overlapped to forming coverage film. Bacteria density of SY is higher.We can clearly see from the figure $1(\mathrm{~d})$ and 2 (d) that the bore of SY was uneven, probably because that the hole adsorbed a lot of petroleum hydrocarbons and enzymes or substances metabolized and so on.Overall, the carrier material had obvious regular cylindrical pore structure, bacteria can be adsorbed on

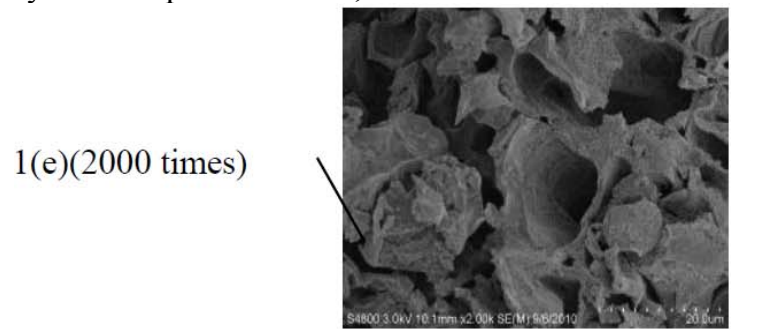

the surface. The amount of rod-shaped bacteria attached to SY is more than MG, the degrading rate of SY was higher than MG. The reason is that the surface roughness of SY is higher than MG, numerous studies [11]. High surface roughness was greatly beneficial to bacteria adsorption and was not easy to fall off, accumulated bacteria amount promote the formation of biofilm. Developed gap structure can absorb some enzymes and coenzyme or petroleum hydrocarbon contaminants. The pore size of SY is small and its specific surface area is large, that is beneficial to the adsorption of enzymes and coenzyme secreted by petroleum hydrocarbon degrading bacteria.

FIGURE I.(E) INTERNAL STRUCTURE OF SY IMMOBILIZED BACTERIA AFTER DEGRADATION. FIG. 2(E) INTERNAL STRUCTURE OF MG IMMOBILIZED BACTERIA AFTER DEGRADATION

It can be seen evidently from the figure 1(e) and 2(e) that the porous structure of SY remains relatively intact, while the hole wall of MG were of perforation and tear after degradation.In comparison, carrier material SY whose structure is relatively stable was more conducive to immobilize microorganisms, it can reduce the damage of external fluid shock, erosion and other adverse factors, can stably maintain microbial cells density per unit volume of medium in a complex environment and can maintain long-term activity, thereby increasing petroleum hydrocarbon degradation rate. So the ideal carrier is those having stability of being resistant to physical degradation, chemical degradation and biodegradation.
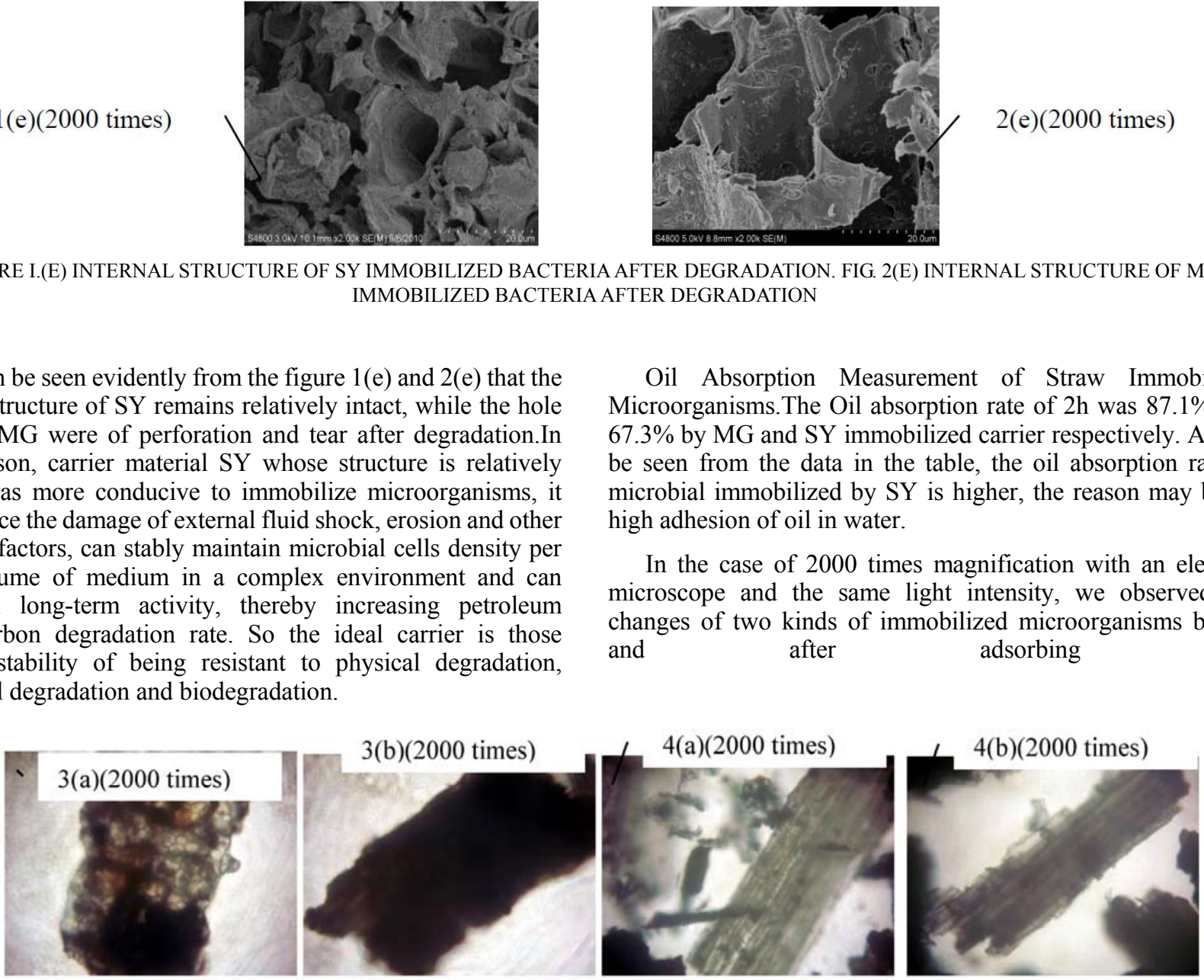

FIGURE III. SY IMMOBILIZED BACTERIA STRUCTURE BEFORE AND AFTER ADSORBED OIL (A AND B). FIG. 4 MG IMMOBILIZED BACTERIA STRUCTURE BEFORE AND AFTER ADSORBED OIL (A AND B)

It was obviously can be seen from figure 3(a) and 4(a) that fibrous network of microorganisms immobilized by two carriers material before the adsorption was clear. It can also be obviously seen from the figures there were a large amount of black oil bonding with the fibers after the oil adsorption of immobilized microorganisms. Before oil absorption, photograph of microorganisms immobilized by SY was darker with respect to
Oil Absorption Measurement of Straw Immobilized Microorganisms. The Oil absorption rate of $2 \mathrm{~h}$ was $87.1 \%$ and $67.3 \%$ by MG and SY immobilized carrier respectively. As can be seen from the data in the table, the oil absorption rate of microbial immobilized by SY is higher, the reason may be its high adhesion of oil in water.

In the case of 2000 times magnification with an electron microscope and the same light intensity, we observed the changes of two kinds of immobilized microorganisms before and after adsorbing oil.
MG, which was consist with the SEM results that surface roughness of SY was larger than MG. Meanwhile we can also observe a lot of gaps and voids in SY. Carrier material MG had smooth surface relatively, its structure was uniform, its hole was elongated and its amount of gap was significantly smaller than SY. As can be seen from figure 3(b) and 4(b), after oil adsorption, voids and cavities in SY were filled with oil, and 
they overall looked more uniform, and small holes were gone basically and black substance sticked together. Oil adsorbed by MG was less and not uniform or the oil adhesive to the surface was washed away by flow easily. They all illustrated that carrier material has uneven and coarse structure was more conducive to the oil adsorption.

The hydrophobicity of petroleum hydrocarbon largely hindered its contact with microorganisms. That was why hydrocarbon must be in contact with the microorganisms, and only with this, hydrocarbons can contact with degrading enzymes through cell wall. So carrier material conducive to oil adsorption can increase contect between efficiency petroleum hydrocarbon degrading bacteria and the oil, thereby increasing the degradation rate of petroleum hydrocarbons.

\section{CONCLUSION}

(1)Immobilization rate of carrier SY of efficient petroleum hydrocarbon degrading bacteria was higher than carrier MG, the petroleum hydrocarbon degradation rate of microorganisms immobilized by carrier SY is higher than carrier MG.

(2)There were obvious cylindrical pore structure in the straw carrier, bacteria was adsorbed onto the surface of the carrier. The immobilized microorganism had fiber network structure, its surface and gap structure were the place of oil adsorption.

(3)SY was the ideal carrier of microorganism immobilization, its high surface roughness was helpful to adsorb efficient petroleum hydrocarbon degrading bacteria, its large specific surface area was conducive to adsorb enzyme and coenzyme secreted by microorganism, high mechanical strength and stable structure was conducive to resist damage of external adverse factors, gap structure and rough surface was helpful for oil adsorption.

\section{ACKNOWLEDGEMENT}

This research was financially supported by the Natural fund of Shandong Province, PR.China.

\section{REFERENCES}

[1] X.Lin, P.J.Li, P.D.Tai, ect, Research progress on plant-microbial remediation of petroleum contaminated soil, Biology Magazine, 25 (1)(2006) 93-100.

[2] Pashova S, Slokoska L, Physiological aspects of immobilized aspergillus niger cells producing polymethylgalacturonase, Process Biochemistry, $35(1-2)(1999) 15-19$

[3] Lau P S, Tam N F Y, Wong Y S, Effect of carrageenan immobilization on the physiological activities of chlorella valgaris, Bioresoure Technology, 63 (2)(1998) 115-121.

[4] G.Y.Xu, S.Q.Shen, J.J.Hu, ect, Experiment of microscopic structure change of straw in condition of cold compression molding. Journal of Solar Energy, 31 (3)(2010) 273-278.

[5] Mona K. Gouda, Sanaa H. Omar, Hemdan M. Nour Eldin, et al., Bioremediation of kerosene II: a case study in contaminated clay (Laboratory and field: scale microcosms), World Journal Microbiol Biotechnology, 24 (8)(2008) 1451-1460.

[6] Yuedong Zhang, Yujiu Ma, Fangxiao Yang, et al . , Continuous acetone-butanol-ethanol production by corn stalk immobilized cells, Journal Industrial Microbiol Biotechnology, 36 (8)(2009) 1117-1121.

[7] O. Rubilar, G. Tortella, M. Cea, et al. , Bioremediation of a Chilean
Andisol contaminated with pentachlorophenol (PCP) by solid substrate cultures of white-rot fungi , Biodegradation, 22 (1)(2011) 31-41.

[8] Podorozhko, Elena A., Lozinsky, et al. , Hydrophobised sawdust as a carrier for immobilisation of the hydrocarbon-oxidizing bacterium Rhodococcus rubber, Bioresource Technology, 99 (2008) 2001-2008.

[9] De Castro H. F., De Lima R., Roberto I. C., Rice straw as a support for immobilization of microbial lipase. Biotechnology Progress, 17 (6)(2001) 1061-1064.

[10] Vega F.A., Covelo E.F., Andrad M.L., Effects of sewage sludge and barley straw treatment on the sorption and retention of $\mathrm{Cu}, \mathrm{Cd}$ and $\mathrm{Pb}$ by coppermine Anthropic Regosols, Journal of Hazardous Materials, 169 $(1-3)(2009)$ 36-45.

[11] Cho Jun Sik, Han Younggun, Jerome J Cuomo, Ion beam pretreatment of polymeric substrates for ITO thin film depo-sition. Solid State Sciences, 10 (7)(2008) 941-949 